\title{
PENGARUH LATIHAN DRILL TERHADAP KEMAMPUAN SERVIS BACKHAND BULUTANGKIS SISWA MTS TARBIYAH ISLAMIYAH KECAMATAN AIR NAPAL BENGKULU UTARA
}

\author{
Feber Kholison
}

PENJAS FKIP UNIB, e-mail: Feberkholison@yahoo.com

\author{
Sugiyanto \\ Universitas Bengkulu \\ Ari Sutisyana \\ Universitas Bengkulu \\ Defliyanto \\ Universitas Bengkulu
}

\begin{abstract}
Abstrak
Penelitian ini bertujuan untuk mengetahui apakah ada pengaruh latihan drill terhadap kemampuan servis backhand bulutangkis siswa MTs Tarbiyah Islamiyah, Kecamatan Air Napal, Bengkulu Utara. Metode penelitian yang digunakan adalah metode eksperimen one group pre-test post-test design dengan variabel bebas adalah latihan drill dan variabel terikat adalah terhadap kemampuan servis backhand bulutangkis. Sampel yang digunakan pada penelitian ini adalah siswa MTs Tarbiyah Islamiyah Kecamatan Air Napal Bengkulu Utara sebanyak 30 siswa. Instrumen penelitian servis backhand bulutangkis validitas dengan sebesar 0,66 dan reliabilitas 0,88. Hasil analisis statistik data menunjukkan latihan drill memberikan pengaruh yang lebih baik terhadap peningkatan kemampuan servis backhand bulutangkis hal ini karena $t_{\text {hitung }} 10.28$ dan $t_{\text {tabel }}$ dengan taraf signifikan $\alpha 5 \%$ diperoleh nilai sebesar 2.000 . Kesimpulan penelitian adalah latihan drill dapat meningkatkan kemampuan servis backhand bulutangkis siswa MTs Tarbiyah Islamiyah, Kecamatan Air Napal, Bengkulu Utara.
\end{abstract}

Kata Kunci : Drill, Servis backhand bulutangkis.

\begin{abstract}
This study aims to determine wheter there is influence drill exercises on service skill MTs Tarbiyah Islamiyah District Air Napal North Bengkulu students. This research method used is experimental method one group pre-test post-test design with free variable is drill exercise and the dependent variable is on badminton backhand service capability. The sample used in this research is MTs Tarbiyah Islamiyah District Air Napal North Bengkulu student as many as 30 people. This instrument research badminton backhand service with validity of
\end{abstract}


0,66 and reliability 0,88 . The results of statistical analysis of data drill exercise gives effect which is better against badminton backhand service capability this is because $t_{h} 10.28$ and $t_{t}$ with significant level $\alpha 5 \%$ obtained value of 2.000 . The conclusion of this study is drill exercise can improve ability badminton backhand service MTs Tarbiyah Islamiyah District Air Napal North Bengkulu students.

Keywords : Drill, Badminton backhand service.

\section{PENDAHULUAN}

Pendidikan

merupakan

bagian terpenting dalam setiap kehidupan manusia. Didalam dunia pendidikan berbagai macam ilmu diajarkan, baik pendidikan formal maupun nonformal. Pendidikan formal disekolah dijalankan secara terencana oleh guru mata pelajaran masing-masing. Proses interaksi antara guru dan siswa di sekolah tidak dapat dipisahkan dalam kesehariannya, dan terdapat proses pendidikan yang mendalam yang dilakukan oleh seorang guru kepada peserta didik, mengembangkan dan membina siswa dalam setiap proses pembelajaran.

Berdasarkan Undang-Undang Dasar 1945 pasal 31 ayat 1 bahwa setiap orang berhak mendapatkan pendidikan dan pengajaran (UUD 1945:163). Baik pendidikan formal atau nonformal setiap orang berhak mendapatkannya tanpa terkecuali termasuk pendidikan jasmani. Seorang guru juga dituntut secara kreatif dan inovatif untuk memberikan materi dan wawasan agar anak berfikir kritis dan mampu membuka wawasan baru serta anak tidak merasa bosan dengan materi yang diajarkan oleh seorang guru. Proses pembelajaran yang kreatif dan inovatif juga akan membuat anak merasa senang dan nyaman terutama dalam pembelajaran

pendidikan jasmani yang menuntut agar anak selalu dapat bergerak.

Pendidikan Jasmani pada dasarnya merupakan bagian integral dari pendidikan secara keseluruhan yang berisikan serangkaian materi pelajaran yang ada dalam kehidupan upaya meningkatkan pertumbuhan dan perkembangan jasmani dan rohani peserta didik. Pendidikan jasmani memiliki kelengkapan sebagai pendidikan yang utuh melibatkan tiga domain penting tujuan pendidikan yaitu aspek kognitif, afektif, dan psikomotor. Pendidikan jasmani merupakan salah satu pelajaran yang diajarkan di sekolah. Karena kesegaran jasmani merupakan bagian yang sangat penting dalam menjalani aktivitas sehari-hari, baik dalam kegiatan belajar, dalam bekerja, dan lain sebagainya.

Sejarah mencatat bahwa olahraga bulutangkis sebenarnya sudah ada pada abad 2000 SM di Mesir kuno dan China. Dulu rakyat di China menggunakan nama Jianzi untuk menyebut bulutangkis. Perkembangan bulutangkis mulai pesat ketika pada era modern rakyat 
Inggris melakukan permainan yang diberi nama battledores, sehingga akhirnya pada abad ke-19 para tentara Britania menyempurnakan permainan bulutangkis ini dengan menambahkan net/jaring yang dipasangkan untuk memisahkan pemain yang saling berlawanan dan ini terdapat di daerah sekitar wilayah Pune, India. Permainan di India tersebut dinamakan dengan Poon. (Teguh Sutanto, 2016:121).

Perkembangan bulutangkis semakin pesat hingga akhirnya dibentuklah organisasi dunia yang menaungi bulutangkis pertama kali pada tahun 1934 yaitu International Badminton Federation (IBF). Saat pertemuan Extraordinary General Meeting di Madrid pada september 2006, ada yang mengusulkan perubahan nama induk organisasi dari International Badminton Federation (IBF) menjadi Badminton World Federation (BWF), kemudian usulan itu diterima oleh seluruh delegasi yang hadir pada saat itu. Di Indonesia sendiri organisasi yang menaungi bulutangkis adalah PBSI (Persatuan Bulutangkis Seluruh Indonesia) didirikan pada tanggal 5 Mei 1951 di Kota Bandung, (Teguh Sutanto, 2016:129). Melihat peminat olahraga bulutangkis sangat pesat ternyata sampai hari ini tidak heran bahwa olahraga bulutangkis merupakan olahraga yang sangat banyak digemari oleh banyak orang saat ini.

Bulutangkis merupakan salah satu cabang olah raga yang menjadi andalan Indonesia dalam mengharumkan nama bangsa dan negara di mata dunia. Tidak terhitung banyaknya prestasi yang telah diukir oleh anak bangsa pada cabang olahraga bergengsi ini. Di Indonesia olahraga bulutangkis mengalami perkembangan pesat. Olahraga ini menarik minat berbagai kelompok masyarakat. Pria maupun wanita dapat memainkan olahraga ini didalam maupun diluar ruangan. Bulutangkis tidak hanya digemari orang dewasa saja, tetapi anak-anak, remaja hingga orang tua senang memainkan olahraga ini.

Olahraga bulutangkis pada saat ini dominasi Indonesia tidak sekuat dulu pada tingkat dunia. Indonesia yang dulunya merupakan negara yang disegani dan salah satu paling ditakuti pada olahraga bulutangkis, sekarang menjadi negara yang dianggap setara dengan yang lainnya. Manajemen olahraga bulutangkis di Indonesia perlu ditingkatkan baik melalui pembelajaran disekolah, terutama dalam pemerataan pembinaan prestasi di klub bulutangkis hingga ke pelosok desa.

Fakta yang terjadi dilapangan atau disekolah-sekolah ternyata masih sangat banyak peserta didik yang tidak memahami dan belum mampu mempraktikkan cara memegang raket yang benar. Seringkali siswa-siswi di sekolah salah dalam mempraktikkan memegang raket, sehingga hasil pukulan raket terhadap shuttlecock kurang memuaskan. Servis backhand pada dasarnya merupakan pukulan 
dasar yang harus bisa dipelajari oleh setiap atlet, selain pukulan servis forehand. Siswa-siswi disekolah seharusnya mampu menguasai teknik dasar servis backhand dengan baik dan seorang guru juga sebagai fasilitator harus siap memberikan solusi atau metode yang tepat agar peserta didik mampu menguasai kemampuan servis backhand.

Hal ini tidak hanya terjadi
pada sekolah-sekolah dengan fasilitas olahraga yang kurang, akan tetapi juga terjadi disekolah-sekolah yang cukup lengkap fasilitas olahraganya. Menurut peneliti sebagian besar sekolah menengah pertama di Bengkulu Utara masih sangat banyak yang membutuhkan perhatian serius serta tambahan fasilitas sarana dan prasarana untuk siswa berolahraga. Sarana dan prasarana yang memadai tentu akan memudahkan peserta didik mengembangkan bakatnya. Selain itu juga latihan-latihan serta klub olahraga harus ditingkatkan baik secara kualitas maupun kuantitas khususnya club bulutangkis. Dengan adanya klub atau tempat peserta didik berlatih tentu saja akan lebih memudahkan anak untuk mengembangkan bakatnya, terutama dalam menguasai teknik dan kemampuan dasar bulutangkis khususnya servis backhand.

\section{Berdasarkan hasil} pengamatan yang dilakukan pada tanggal 3 Desember 2017 dari jumlah 30 siswa yang dapat melakukan servis backhand dengan baik hanya $20 \%$, maka penulis menentukan judul penelitian dengan judul "Pengaruh Latihan Drill Terhadap Kemampuan Servis Backhand Bulutangkis Siswa Mts Tarbiyah Islamiyah Kecamatan Air Napal Bengkulu Utara".

\section{METODE}

Jenis dari penelitian ini merupakan penelitian Eksperimen pre-experimental design (One-group pretest-posttest design) Sugiyono, (2010:110). Metode eksperimen merupakan metode yang digunakan untuk mencari pengaruh treatment (perlakuan) tertentu. Menurut Sugiyono (2010:13) metode penelitian kuantitatif ini juga sering disebut sebagai metode positivistik karena berlandaskan pada filsafat positivisme. Penelitian ini akan dilaksanakan di lapangan bulutangkis MTs Tarbiyah Islamiyah, Kecamatan Air Napal, Bengkulu Utara. Waktu penelitian ini dilaksanakan selama 16 kali pertemuan dengan frekuensi latihan 3 kali seminggu dimulai pada semester genap tahun ajaran 2017/2018 pada tanggal 12 Maret 2018 sampai 20 April 2018. sampel yang diambil adalah sampel kelompok (Dian dan Bayu 2013:74), kelompok pelajar kelas VIII B yang berjumlah 18 orang laki-laki dan 12 orang perempuan dengan total keseluruhan sampel 30 orang siswasiswi MTs Tarbiyah Islamiyah, Kecamatan Air Napal, Bengkulu Utara.

\section{HASIL DAN PEMBAHASAN \\ Hasil}


1. Hasil uji normalitas data tes awal menunjukkan thitung $-6,3852$ dan $t_{\text {tabel }} 11,070$. Hasil uji normalitas data tes akhir menunjukkan $t_{\text {hitung }}$ $-27,995$ dan $t_{\text {tabel }} 11,070$. Apabila data $t_{\text {hitung }}<t_{\text {tabel }}$ maka data berdistribusi normal, sedangkan hasil uji normalitas data tes awal dan tes akhir menunjukkan thitung $<t_{\text {tabel }}$ artinya data berdistribusi normal.

2. Hasil uji homogenitas varians tes awal dan tes akhir, thitung 1,87 dan $t_{\text {tabel }} 4,18$. Apabila $t_{\text {hitung }}<t_{\text {tabel }}$ maka varians data homogen, sedangkan hasil uji homogenitas varians menunjukkan $t_{\text {hitung }}<t_{\text {tabel }}$ artinya data bervarians homogen.

3. Hasil uji hipotesis penellitian menggunakan uji $t$, hasil thitung 10,28 dan $t_{\text {tabel }}$ pada taraf signifikansi $\alpha 0,05$ dengan $\mathrm{dk}=58$ adalah 2,000. Apabila $t_{\text {hitung }}>t_{\text {tabel }}$ maka $\mathrm{Ha}$ diterima, sedangkan hasil uji $t$ menunjukkan $t_{\text {hitung }}>$

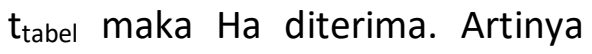
ada pengaruh latihan drill terhadap kemampuan servis backhand bulutangkis siswa MTs Tarbiyah Islamiyah Kecamatan Air Napal Bengkulu Utara.

\section{PENUTUP}

\section{Simpulan}

Hasil analisis data statistik membuktikan $t_{\text {hitung }}>t_{\text {tabel, }}$ dari hasil uji $t$ thitung diperoleh sebesar 10.28 dan $t_{\text {tabel }}$ diperoleh angka dengan taraf signifikan $\alpha$ 0,05 diperoleh nilai sebesar 2.00. Didapatkan nilai rata- rata mean $(\bar{X})$ dari data statistik tes awal diperoleh sebesar 18,43 dan tes akhir diperoleh sebesar 22,8. Artinya latihan drill dapat meningkatkan kemampuan servis backhand bulutangkis siswa MTs Tarbiyah Islamiyah Kecamatan Air Napal Bengkulu Utara.

\section{Saran}

Adapun saran-saran yang dapat penulis sampaikan dalam hasil penelitian ini adalah :

1. Bagi siswa agar bisa memahami totalitas dalam latihan agar kondisi fisik, teknik, dan kemampuan terus meningkat.

2. Bagi pelatih atau guru, olahraga bulutangkis latihan drill selalu diterapkan selama proses latihan sehingga siswa atau atlit benarbenar matang dalam menguasai teknik atau kemampuan tertentu. Sebaiknya didalam setiap sesi latihan siswa diberikan kesempatan bermain dilapangan agar bisa dipraktikkan secara langsung dan dapat juga diketahui pencapaian hasil 
selama proses latihan telah dilakukan.

3. Skripsi ini supaya dijadikan acuan dalam pemberian menu pembelajaran bagi siswa atau atlit bulutangkis khususnya disekolah-sekolah di Bengkulu, dan dapat membuka ide baru bagi guru olahraga atau pelatih bulutangkis.

\section{DAFTAR PUSTAKA}

Dian pujianto dan Bayu Insanistyo. (2013). Dasar Dasar Penelitian Pendidikan

Jasmani. Bengkulu: FKIP PRESS Universitas

Bengkulu.

Sekretariat Jendral MPR RI, (2014). UUD 45 yang diamandemen. Jakarta: MPR RI.

Sugiyono. (2010). Metode Penelitian Pendidikan Pendekatan Kuantitatif, Kualitatif, dan $R \& D$. Bandung:

ALFABETA.

Sutanto, Teguh. (2016). Buku Pintar Olahraga. Yogyakarta: Pustaka Baru Press.

Tangkudung, James. (2012). Kepelatihan Olahraga Pembinaan Prestasi Olahraga. Jakarta: Cerdas jaya
Metodologi Penelitian. Jakarta:

Lensa Media Pustaka Indonesia ,(2018).

Sport

Psychometrics Dasar-dasar dan instrument Psikometri. Depok :Rajagrafindo persada 